Article

\title{
Field-Induced SMM and Vis/NIR Luminescence on Mononuclear Lanthanide Complexes with 9-Anthracenecarboxylate and $2,2^{\prime}: 6,2^{\prime \prime}$-Terpyridine
}

\author{
Berta Casanovas $^{1}$, Oriol Porcar ${ }^{1}$, Saskia Speed ${ }^{1, *}$, Ramon Vicente ${ }^{1}$, Mercè Font-Bardía ${ }^{2}$ \\ and Mohamed Salah El Fallah 1,*
}

1 Departament de Química Inorgànica i Orgànica, Secció de Química Inorgànica and and Institut de Nanociència i Nanotecnologia (IN2UB), Universitat de Barcelona, Martí i Franquès 1-11, 08028 Barcelona, Spain; berta.casanovas@qi.ub.es (B.C.); oriol.porcar@ub.edu (O.P.); ramon.vicente@qi.ub.es (R.V.)

2 Departament de Mineralogia, Cristal-Lografia i Dipòsits Minerals and Unitat de Difracció de RX, Centre Científic i Tecnològic de la Universitat de Barcelona (CCiTUB), Universitat de Barcelona, C/Solé i Sabarís, 1-3, 08028 Barcelona, Spain; mercef@ccit.ub.edu

* Correspondence: saskia.speed@qi.ub.es (S.S.); salah.elfallah@qi.ub.es (M.S.E.F.); Tel.: +34-93-4039134 (M.S.E.F.)

Citation: Casanovas, B.; Porcar, O.; Speed, S.; Vicente, R.; Font-Bardía, M.; El Fallah, M.S. Field-Induced SMM and Vis/NIR Luminescence on Mononuclear Lanthanide Complexes with 9-Anthracenecarboxylate and $2,2^{\prime}: 6,2^{\prime \prime}$-Terpyridine Magnetochemistry 2021, 7, 124 https://doi.org/10.3390/ magnetochemistry7090124

Academic Editors: Marius Andruh, Eva Rentschler and Andrea Caneschi

Received: 25 July 2021

Accepted: 6 September 2021

Published: 10 September 2021

Publisher's Note: MDPI stays neutral with regard to jurisdictional claims in published maps and institutional affiliations.

Copyright: (c) 2021 by the authors. Licensee MDPI, Basel, Switzerland. This article is an open access article distributed under the terms and conditions of the Creative Commons Attribution (CC BY) license (https:// creativecommons.org/licenses/by/ $4.0 /)$.

\begin{abstract}
Five new mononuclear lanthanide complexes are synthesized by adding the several lanthanide nitrate hexahydrate salts, which for lanthanide ( $\mathrm{Ln}$ ) are $\mathrm{Eu}, \mathrm{Tb}, \mathrm{Dy}, \mathrm{Er}$, and $\mathrm{Yb}$, with 9-anthracenecarboxylic acid (9-Hanthc) and 2,2':6,2' -terpyridine (TPY) in mixed solution of methanol and dimethylformamide (DMF). The general formula is $\left[\mathrm{Eu}(9 \text {-anthc })_{3}(\mathrm{TPY})(\mathrm{DMF})\right] \cdot \mathrm{H}_{2} \mathrm{O}(\mathbf{1 E u})$ where $\mathrm{Eu}(\mathrm{III})$ is ennea-coordinated or $\left[\mathrm{Ln}(9 \text {-anthc })_{3}(\mathrm{TPY})\left(\mathrm{H}_{2} \mathrm{O}\right)\right] \cdot \mathrm{H}_{2} \mathrm{O} \cdot \mathrm{DMF}(\mathrm{Ln}=\mathrm{Tb}(\mathbf{2 T b})$, Dy (3Dy), $\mathrm{Er}(4 \mathrm{Er})$, and $\mathrm{Yb}(\mathbf{5 Y b})$ ) where $\mathrm{Ln}(\mathrm{III})$ is octa-coordinated. For compounds $3 \mathrm{Dy}, 4 \mathrm{Er}$, and $5 \mathrm{Yb}$, the dynamic ac magnetic study indicated field-induced single molecule magnet (SMM) behavior. The photoluminescence studies in the solid state of these complexes show the sensitization of $4 f-4 f$ transitions for $4 \mathrm{Er}$ and $5 \mathrm{Yb}$ in the NIR region.
\end{abstract}

Keywords: lanthanide(III) ions; coordination compounds; single-molecule magnets; luminescence

\section{Introduction}

In recent years, coordination complexes with lanthanide ions have been extensively studied because of their interesting magnetic and luminescent properties. The magnetic interest arises from the high magnetic momentum of the lanthanide ions and strong magnetic anisotropy of its ground state widely used in the molecular magnetism area to design single-molecule magnets (SMMs) that provide potential in information storage, quantum computation, and spintronics [1-8]. In SMMs lanthanide compounds, the energy needed to reverse the magnetization, and the gaps energy between the emission contributions, result in the sublevel structure of the Stark components. In addition, the magnetic relaxation occurs through different process such as Orbach one, direct relaxation, Raman mechanism, or Quantum Tunneling of the Magnetization (QTM). In many cases, these processes can occur conjunctly. Therefore, to optimize the SMMs characteristics, the involved mechanism in the magnetic relaxation and the factors that affect them have to be understood. One of the used strategies to better understand the magnetic properties is to take advantage of the correlation between the magnetic and optical properties of the luminescent SMM compounds. Photoluminescent studies may allow spectroscopic detection of the energy splitting of the $\mathrm{m}_{J}$ states of $\operatorname{Ln}(\mathrm{III})$ that can be compared with the magnetic results obtained [9-25].

Regarding the optical aspect, Ln(III)-based materials manifest exceptional luminescence characteristics, with high emission quantum yields, narrow bandwidths, ligandinduced large Stokes shifts, long-lived emission, and ligand-dependent luminescence 
sensitization [26]. Nevertheless, due to the limited extinction degree of the $f-f$ transitions prohibited by Laporte rules [27], the Lanthanide ions must be excited indirectly by the energy transfer proceedings of organic ligands known as antenna that have a large extinction degree $(\varepsilon)$. Then, the excitation energy is transmitted as characteristic narrow $f-f$ emission bands in the visible and/or in near-infrared (NIR) spectral ranges [28]. Lanthanide complexes emitting in the NIR region present interesting applications as solid-state laser materials [29], in telecommunications [30], in optical communication systems [31], in optical amplifiers [32], and in fluoroimmunoassay [33,34]. The intense luminescence from complexes emitting in visible region as $\mathrm{Eu}(\mathrm{III})$ and $\mathrm{Tb}(\mathrm{III})$ has generated the development of multiple applications [35-40].

Recently, we have reported three series of dinuclear lanthanide compounds with formulas [ $\mathrm{Ln}_{2}(2-\mathrm{FBz})_{4}\left(\mathrm{NO}_{3}\right)_{2}(\mathrm{phen})_{2}$ ] [41], [ $\left.\mathrm{Ln}_{2}\left(\mu_{2}-9-\mathrm{AC}\right)_{4}(9-\mathrm{AC})_{2}(\mathrm{bpy})_{2}\right]$ [42], and $\left[\operatorname{Ln}_{2}(\mu-\right.$ 2-FBz $\left.)_{2}(2-\mathrm{FBz})_{4}(\text { terpy })_{2}\right] \cdot 2(\mathrm{H}-2-\mathrm{FBz}) \cdot 2\left(\mathrm{H}_{2} \mathrm{O}\right)$ [43]. In these series, $\mathrm{Nd}, \mathrm{Er}$, and $\mathrm{Yb}$ dinuclear compounds exhibit field-induced SMM behavior and NIR-luminescence; thus, they can be considered as multifunctional compounds. We aim to enhance and expand the results obtained in the synthesis of new complexes and induce structural change that may cause variations in magnetic and luminescence behavior. Another reason that led us to such an investigation is the scarce lanthanide metals with 9-anthracenecarboxylate compounds described in the literature. According to the Cambridge Structural Database (CSD) [44], barely twenty-two coordination complexes have been structurally characterized with only lanthanide metals and 9-anthracenecarboxylate: one $\mathrm{Yb}$ (III) compound with mononuclear structure, [45] twenty dinuclear compounds with different lanthanide metals where ten of them are reported by us [41-43] and the other ten are described by Liu [46-48], Wang [49], and $\mathrm{Wu}[50]$, and finally one dinuclear compound of $\operatorname{Er}(\mathrm{III})$ showing monodimensional structure [45]. Thus, this time, we have combined the ligand 2,2' $: 6^{\prime}, 2^{\prime \prime}$-terpyridine (TPY), 9anthracenecarboxylic acid (9-Hanthc), and lanthanide sales. This has allowed the isolation of five new mononuclear complexes of formula [Eu(9-anthc) $\left.{ }_{3}(\mathrm{TPY})(\mathrm{DMF})\right] \cdot \mathrm{H}_{2} \mathrm{O}(\mathbf{1 E u})$ where $\mathrm{Eu}(\mathrm{III})$ is ennea-coordinated or $\left[\mathrm{Ln}(9 \text {-anthc })_{3}(\mathrm{TPY})\left(\mathrm{H}_{2} \mathrm{O}\right)\right] \cdot \mathrm{H}_{2} \mathrm{O} \cdot \mathrm{DMF}(\mathrm{Ln}=\mathrm{Tb}(\mathbf{2} \mathbf{T b})$, Dy (3Dy), Er (4Er), and $\mathrm{Yb}(\mathbf{5} \mathrm{Yb})$ ) where the $\mathrm{Ln}(\mathrm{III})$ ions are octa-coordinated. The new compounds were characterized by $\mathrm{X}$-ray diffraction, and their magnetic and luminescent properties were studied.

\section{Results and Discussion}

\subsection{X-ray Crystal Structures}

Complexes 1Eu-5 $\mathbf{Y b}$ present two different structures depending on the atomic radii of the lanthanide ion. For the largest Eu(III), the lanthanide ion is ennea-coordinated and presents a type I structure. On the other hand, for small lanthanides, the coordination is eight and presents a type II structure. As complexes $\mathbf{2} \mathbf{T b}-\mathbf{5} \mathbf{Y b}$ are isostructural, only the structures of compounds $1 \mathrm{Eu}$ and $4 \mathrm{Er}$ will be discussed in detail. The most relevant parameters for single crystal determination are collected in Table 1 in the Materials and Methods section.

\subsubsection{Structural Type I: $\left[\mathrm{Eu}(9 \text {-anthc })_{3}(\mathrm{TPY})(\mathrm{DMF})\right] \cdot \mathrm{H}_{2} \mathrm{O}(1 \mathrm{Eu})$}

Complex $1 \mathrm{Eu}$ of formula [Eu(9-anthc $\left.)_{3}(\mathrm{TPY})(\mathrm{DMF})\right] \cdot \mathrm{H}_{2} \mathrm{O}$ crystallizes in the monoclinic space group $\mathrm{P}_{1}$ /c. A partially labeled plot of the $\mathrm{Eu}(\mathrm{III})$ mononuclear complex is presented in Figure 1a. Selected bond distances are listed in Table 2. The structure of 1Eu consists of [Eu(9-anthc $\left.)_{3}(\mathrm{TPY})(\mathrm{DMF})\right]$ molecules in which each $\mathrm{Eu}(\mathrm{III})$ ion is ennea-coordinated with a EuN $\mathrm{E}_{3} \mathrm{O}_{6}$ coordination environment formed by a tridentate TPY ligand, two chelating 9-anthc ligands, one monodentate 9-anthc ligand, and a coordinated DMF solvent molecule. Three of the coordination sites around the central atom are occupied by the N1, N2, and $\mathrm{N} 3$ atoms of a TPY ligand, with Eu-N bond distances equal to 2.552 (3), 2.606 (3), and 2.545 (3) $\AA$, respectively. In addition, the Eu(III) central atom is coordinated to five oxygen atoms from three different 9 -anthc ligands. Two of the 9 -anthc ligands show a chelating coordination mode with Eu1-O1 and Eu1-O2 bond distances of 2.421 (3) and 2.574 (3) $\AA$ and 
Eu1-O3 and Eu1-O4 distances of 2.465 (3) and 2.599 (3) $\AA$, while the third 9-anthc ligand is coordinated in the monodentate mode with an Eu1-O5 bond distance of 2.279 (3) $\AA$. The ennea-coordinated sphere of $\mathrm{Eu}(\mathrm{III})$ is completed by the $\mathrm{O} 7$ oxygen atom from a DMF solvent molecule with an Eu1-O7 bond distance of 2.410 (3) A.

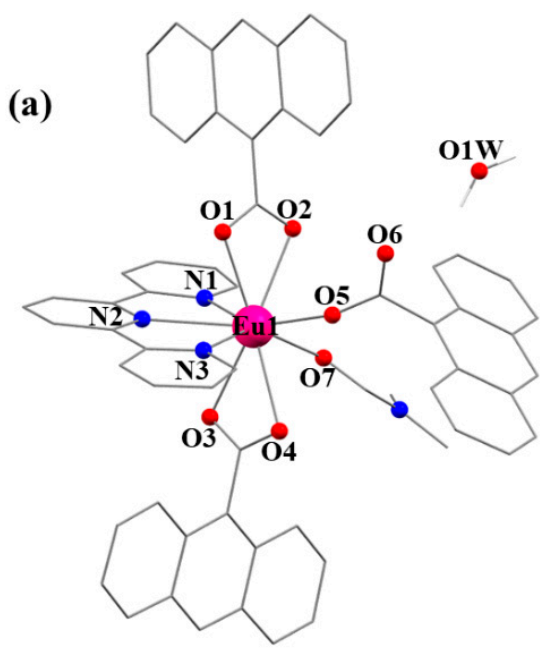

(b)

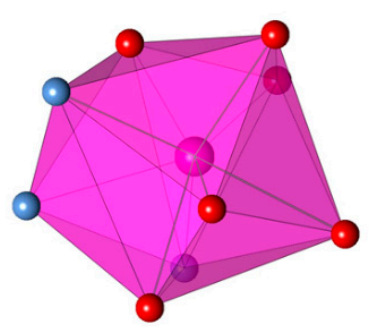

Figure 1. (a) Structure of 1Eu partially labeled. Hydrogen atoms are omitted for clarity. Color code: gray $=\mathrm{C}$, blue $=\mathrm{N}$, red $=\mathrm{O}$ and pink $=\mathrm{Eu}$. (b) Coordination polyhedron of the $\mathrm{Eu}(\mathrm{III})$ ion in 1Eu.

Table 1. Crystallographic data and data collection details for the X-ray structures of 1Eu-5Yb.

\begin{tabular}{|c|c|c|c|c|c|}
\hline & 1Eu & $2 \mathrm{~Tb}$ & 3Dy & $4 \mathrm{Er}$ & $5 \mathrm{Yb}$ \\
\hline Formula & $\mathrm{C}_{63} \mathrm{H}_{47} \mathrm{EuN}_{4} \mathrm{O}_{8}$ & $\mathrm{C}_{63} \mathrm{H}_{49} \mathrm{~N}_{4} \mathrm{O}_{9} \mathrm{~Tb}$ & $\mathrm{C}_{63} \mathrm{H}_{49} \mathrm{DyN}_{4} \mathrm{O}_{9}$ & $\mathrm{C}_{63} \mathrm{H}_{49} \mathrm{ErN}_{4} \mathrm{O}_{9}$ & $\mathrm{C}_{63} \mathrm{H}_{49} \mathrm{~N}_{4} \mathrm{O}_{9} \mathrm{Yb}$ \\
\hline $\mathrm{FW}, \mathrm{g} \cdot \mathrm{mol}^{-1}$ & 1140.01 & 1164.99 & 1168.56 & 1173.32 & 1179.10 \\
\hline System & monoclinic & monoclinic & monoclinic & monoclinic & monoclinic \\
\hline Space group & $\mathrm{P} 2{ }_{1} / \mathrm{c}$ & $\mathrm{P} 2{ }_{1} / \mathrm{n}$ & $\mathrm{P} 2{ }_{1} / \mathrm{n}$ & $\mathrm{P} 2{ }_{1} / \mathrm{n}$ & $\mathrm{P} 2{ }_{1} / \mathrm{n}$ \\
\hline$a, \AA$ & $10.3824(6)$ & $13.9192(8)$ & $13.9408(7)$ & $11.262(1)$ & $11.2612(4)$ \\
\hline$b, \AA$ & 33.0002 (17) & $25.6243(15)$ & $25.5845(12)$ & $17.3804(16)$ & $17.3724(5)$ \\
\hline$c, \AA$ & $14.9696(8)$ & $14.5847(9)$ & $14.5560(6)$ & $26.931(2)$ & $26.9285(9)$ \\
\hline$\beta, \operatorname{deg}$ & $99.981(2)$ & $98.792(2)$ & $98.892(2)$ & $90.316(3)$ & $90.313(1)$ \\
\hline$V, \AA^{3}$ & $5051.3(5)$ & $5140.8(5)$ & $5129.3(4)$ & $5271.3(8)$ & $5268.1(3)$ \\
\hline Z & 4 & 4 & 4 & 4 & 4 \\
\hline$T, \mathrm{~K}$ & $100(2)$ & $100(2)$ & $100(2)$ & $100(2)$ & $100(2)$ \\
\hline$\lambda(\mathrm{MoK} \alpha), \AA$ & 0.71073 & 0.71073 & 0.71073 & 0.71073 & 0.71073 \\
\hline$D_{\text {calc, }} \mathrm{g} \cdot \mathrm{cm}^{-3}$ & 1.499 & 1.505 & 1.513 & 1.479 & 1.487 \\
\hline$\mu, \mathrm{mm}^{-1}$ & 1.306 & 1.441 & 1.523 & 1.656 & 1.839 \\
\hline$F(000)$ & 2320 & 2368 & 2372 & 2380 & 2388 \\
\hline Collected & 48902 & 145691 & 64730 & 10859 & 25695 \\
\hline Unique $\left(R_{\text {int }}\right)$ & $9615(0.06)$ & $15595(0.024)$ & $10446(0.043)$ & $10859(0.053)$ & $6774(0.041)$ \\
\hline parameters & 693 & 725 & 699 & 692 & 715 \\
\hline$R_{1}$ & 0.0449 & 0.0188 & 0.0230 & 0.0367 & 0.0312 \\
\hline$w R_{2}$ & 0.0787 & 0.0535 & 0.0668 & 0.0756 & 0.0841 \\
\hline Goodness of fit & 1.18 & 0.97 & 0.99 & 1.18 & 1.09 \\
\hline
\end{tabular}

Table 2. Selected bond distances $(\AA)$ for $\mathbf{1 E u - 5 Y b . ~}$

\begin{tabular}{cccccc}
\hline & $\mathbf{1 E u}$ & $\mathbf{2 T b}$ & $\mathbf{3 D y}$ & $\mathbf{4 E \mathbf { r }}$ & $\mathbf{5 Y b}$ \\
\hline Ln1-O1 & $2.421(3)$ & $2.2336(11)$ & $2.2156(16)$ & $2.199(2)$ & $2.176(4)$ \\
Ln1-O2 & $2.574(3)$ & - & - & - & - \\
Ln1-O3 & $2.465(3)$ & $2.3974(10)$ & $2.3772(17)$ & $2.358(2)$ & $2.336(3)$ \\
Ln1-O4 & $2.599(3)$ & $2.4660(9)$ & $2.4552(15)$ & $2.430(2)$ & $2.407(3)$ \\
Ln1-O5 & $2.279(3)$ & $2.2789(11)$ & $2.2698(16)$ & $2.269(2)$ & $2.256(3)$ \\
Ln1-O6 & $2.410(3)$ & $2.4196(11)$ & $2.4084(17)$ & $2.344(2)$ & $2.314(3)$ \\
Ln1-N1 & $2.552(3)$ & $2.5154(10)$ & $2.511(2)$ & $2.488(3)$ & $2.472(3)$ \\
Ln1-N2 & $2.606(3)$ & $2.5522(11)$ & $2.5374(19)$ & $2.479(2)$ & $2.457(3)$ \\
Ln1-N3 & $2.545(3)$ & $2.5098(12)$ & $2.497(2)$ & $2.508(3)$ & $2.489(3)$ \\
\hline
\end{tabular}


The estimation of the coefficients of distortion of the $\mathrm{EuN}_{3} \mathrm{O}_{6}$ coordination polyhedron for $1 \mathrm{Eu}$ in reference to the ideal nine vertex polyhedral was made by employing the continuous shape measure theory and SHAPE software [51,52], showing that the $\mathrm{N}_{3} \mathrm{O}_{6}$ disposition for 1Eu is intermediate between different coordination polyhedra. The best SHAPE estimation led to Muffin (MFF-9, $C_{2 v}$ ), spherical-capped square antiprism (CSAPR-9, $C_{4 v}$ ), and spherical-tricapped trigonal prism (TCTPR-9, $\mathrm{D}_{3 \mathrm{~h}}$ ) geometries with continuous shape measure (CShM) values of 1.678, 2.006, and 2.407, respectively. A graphical representation of the metal coordination geometry of $\mathbf{1 E u}$ is shown in Figure $1 \mathrm{~b}$.

The coordination of [Eu(9-anthc) $)_{3}$ (TPY)(DMF)] forms a hydrogen bond with a molecule of water through the hydrogen atom $\mathrm{H} 1 \mathrm{~W}$ and the oxygen atom $\mathrm{O} 6$ of the monodentate 9anthc ligand (Supplementary Materials, Table S2). In addition, each [Eu(9-anthc) $\left.{ }_{3}(\mathrm{TPY})(\mathrm{DMF})\right]$ molecule forms a $\pi-\pi$ type interaction with a neighboring molecule between the ring containing the N1 atom ( $\mathrm{Cg}(1)$ from the Supplementary Materials, Table S3) and the one containing the N2 atom ( $\mathrm{Cg}(2)$ from the Supplementary Materials, Table S3) of the respective TPY ligands. In addition, the mononuclear compound also forms an intermolecular interaction of the same nature with another neighboring molecule via two anthracene groups of the two corresponding 9-anthc ligands containing O1-O2 oxygens (contact $\mathrm{Cg}(4)$ $\mathrm{Cg}(4)^{\prime}$ from the Supplementary Materials, Table S3). The sum of the two intermolecular contacts forms chains of [Eu(9-anthc $\left.)_{3}(\mathrm{TPY})(\mathrm{DMF})\right]$ units along the direction [110] of the crystalline network with $\mathrm{Eu}(\mathrm{III}) \cdots \mathrm{Eu}(\mathrm{III})$ distances of $8.748 \AA$ (Figure 2).

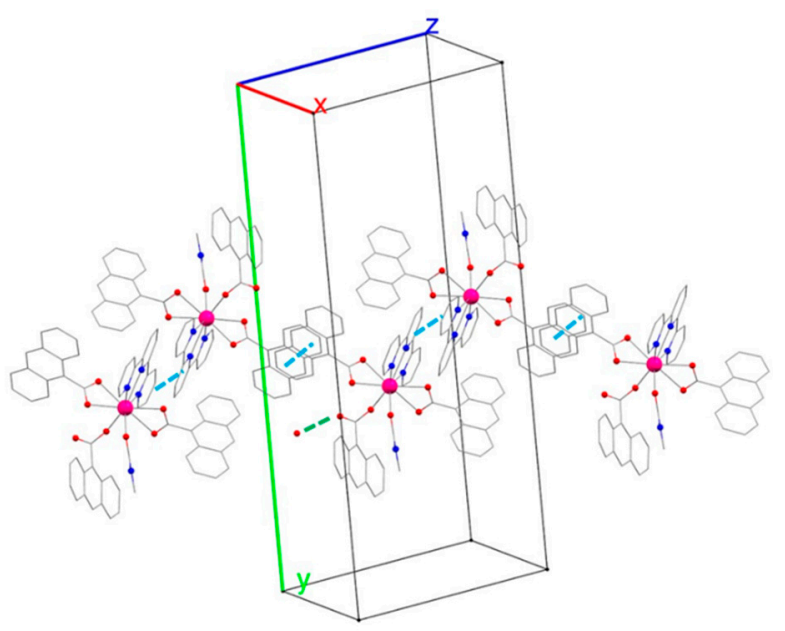

Figure 2. Hydrogen bond (green dashed line) and $\pi-\pi$ stacking (blue dashed lines) in 1Eu.

2.1.2. Structural Type II: $\left[\operatorname{Ln}(9-a n t h c){ }_{3}(T P Y)\left(\mathrm{H}_{2} \mathrm{O}\right)\right] \cdot \mathrm{H}_{2} \mathrm{O} \cdot \mathrm{DMF}(\mathrm{Ln}=\mathrm{Tb}(2 \mathrm{~Tb})$, Dy (3Dy), $\operatorname{Er}(4 \mathrm{Er})$ and $\mathrm{Yb}(5 \mathrm{Yb}))$

Complexes $2 \mathbf{T b}-\mathbf{5 Y b}$ with formula [ $\left.\mathrm{Ln}(9 \text {-anthc })_{3}(\mathrm{TPY})\left(\mathrm{H}_{2} \mathrm{O}\right)\right] \cdot \mathrm{H}_{2} \mathrm{O} \cdot \mathrm{DMF}(\mathrm{Ln}=\mathrm{Tb}$ (2Tb), Dy (3Dy), Er (4Er), and $\mathrm{Yb}(5 \mathrm{Yb})$ ) crystallize in the monoclinic space group P21/n. Selected bond distances for compounds $\mathbf{2} \mathbf{T b}-\mathbf{5} \mathbf{Y b}$ are listed in Table 1 . As an example of the structural type II, $4 \mathrm{Er}$ will be described below (Figure 3).

The structure of compound $4 \mathrm{Er}$ consists of $\left[\mathrm{Er}(9 \text {-anthc })_{3}(\mathrm{TPY})\left(\mathrm{H}_{2} \mathrm{O}\right)\right]$ molecules in which each $\mathrm{Er}(\mathrm{III})$ ion is octa-coordinated. The $\mathrm{Er}(\mathrm{III})$ ion has an $\mathrm{ErN}_{3} \mathrm{O}_{5}$ octa-coordination environment formed by a tridentate TPY ligand, a chelating 9-anthc ligand, two monodentate 9 -anthc ligands, and a water molecule. The octa-coordinated environment of the $\operatorname{Er}(\mathrm{III})$ ion corresponds to four oxygen atoms of three different 9-anthc ligands (O1 and $\mathrm{O} 5$ from two monodentate 9 -anthc ligands and $\mathrm{O} 3$ and $\mathrm{O} 4$ from the chelating 9-anthc ligand, with Er-O average distance of $2.314 \AA$ ), three nitrogen atoms of the TPY ligand (N1, N2 and $\mathrm{N} 3$, with an average Er-N distance of $2.492 \AA$ ), and the oxygen atom from the coordinated water molecule (O7, Er1-O7 bond distance of $2.344 \AA$ ) . 

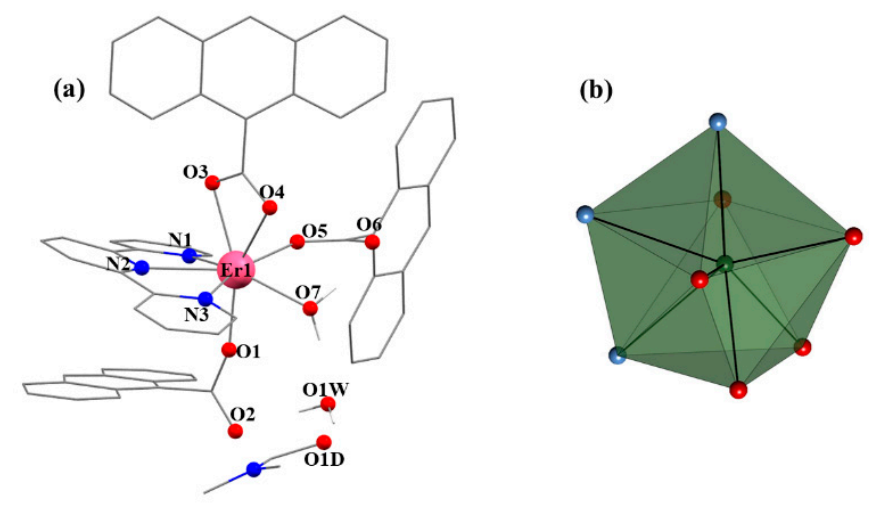

Figure 3. (a) Partially labeled structure of 4 Er. $H$ atoms are omitted for clarity. Color code: gray $=\mathrm{C}$, blue $=\mathrm{N}$, red $=\mathrm{O}$, and light pink $=$ Er. $(\mathbf{b})$ Coordination polyhedron of the $\operatorname{Er}(\mathrm{III})$ ion in 4Er.

The estimation of the coefficient of distortion of the $\mathrm{ErN}_{3} \mathrm{O}_{5}$ coordination polyhedron for $4 \mathrm{Er}$ in reference to the ideal eight vertex polyhedral was made by employing the continuous shape measure theory and SHAPE software and shows that the $\mathrm{N}_{3} \mathrm{O}_{5}$ distribution in $4 \mathrm{Er}$ is intermediate between different coordination polyhedra. The best SHAPE estimation led to triangular dodecahedron (TDD-8, $\mathrm{D}_{2 \mathrm{~d}}$ ), biaugmented trigonal prism (BTPR-8, $\mathrm{C}_{2 \mathrm{v}}$ ), or Johnson-biaugmented trigonal prism (JBTP-8, $\mathrm{C}_{2 \mathrm{v}}$ ) geometries with continuous shape measure (CShM) values of 2.342, 2.426, and 2.516, respectively. A graphical depiction of the metal coordination geometry of $4 \mathbf{E r}$ is shown in Figure $3 \mathrm{~b}$. The result of the estimation of the coefficient of distortion of the $\mathrm{LnN}_{3} \mathrm{O}_{5}$ coordination polyhedron for $\mathbf{2} \mathbf{T b}-\mathbf{5 Y b}$ in reference to the ideal eight vertex polyhedral are reported in Table S1 in the Supplementary Materials.

Compound 4Er presents an intramolecular hydrogen bond between H7A from the water molecule coordinated to $\mathrm{Er}$ (III) and $\mathrm{O} 6$ from one of the 9-anthc ligands coordinated in the monodentate mode. On the other hand, the other hydrogen of this $\mathrm{H}_{2} \mathrm{O}$ molecule, $\mathrm{H7B}$, forms another $\mathrm{H}$ bond with the crystallization water molecule $(\mathrm{O} 1 \mathrm{~W})$. At the same time, both hydrogen atoms of this water molecule also form hydrogen bonds, H1WA with $\mathrm{O} 2$ of a monodentate 9-anthc ligand and H1WB with O1D from a DMF crystallization molecule (Figure 4). The contact distances and angles for compounds $\mathbf{2} \mathbf{T b}-\mathbf{5} \mathbf{Y b}$ are listed in Table S2 from the Supplementary Materials.

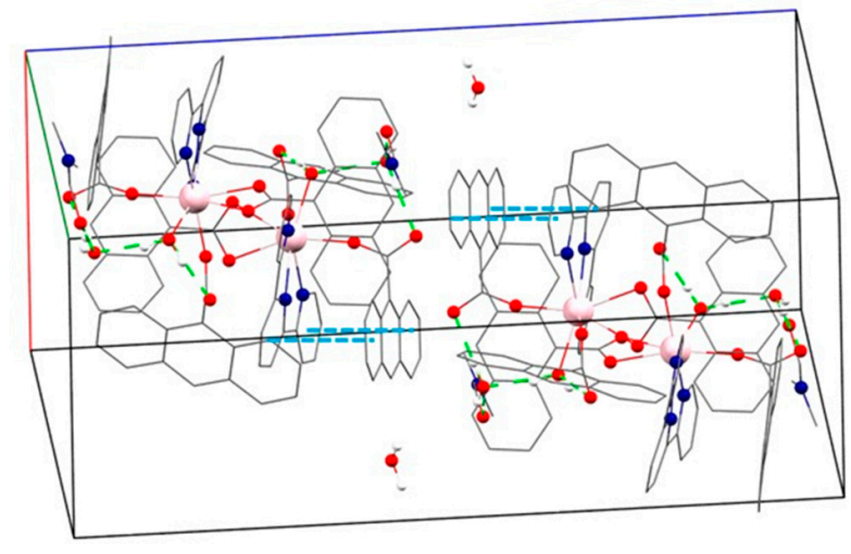

Figure 4. Hydrogen bond (green dashed line) and $\pi-\pi$ stacking (blue dashed lines) in 4Er.

The compounds also present $\pi-\pi$ stacking interactions between different aromatic rings. One of them is given within each molecule [ $\left.\mathrm{Ln}(9 \text {-anthc })_{3}(\mathrm{TPY})\left(\mathrm{H}_{2} \mathrm{O}\right)\right]$ between the TPY ligand rings ( $\mathrm{Cg}(1)$ from the Supplementary Materials, Table S3) and the anthracene group of the monodentate ligand containing the oxygen atoms $\mathrm{O} 1$ and $\mathrm{O} 2\left(\mathrm{Cg}(6)^{\prime}\right.$ or $\mathrm{Cg}(7)^{\prime}$ 
from the Supplementary Materials, Table S3). The intermolecular contacts vary slightly according to the $\mathrm{Ln}$ (III) ion. In the case of the Tb(III) and Dy(III) compounds, the TPY rings of each mononuclear unit interact with two different neighbor molecules via the corresponding terpyridine ligands. Thus, there is an interaction between the ring that contains the $\mathrm{N} 1$ atom with the ring that contains the $\mathrm{N} 2$ atom of a neighboring molecule (Cg (1)-Cg (2)' from the Supplementary Materials, Table S3) and another supramolecular contact of the TPY ligand ring that contains the N3 nitrogen with the same ring of another adjacent molecule (contact $\mathrm{Cg}(3)-\mathrm{Cg}(3)^{\prime}$ from the Supplementary Materials, Table S3). On the other hand, the compounds $\left[\mathrm{Ln}(9 \text {-anthc })_{3}(\mathrm{TPY})\left(\mathrm{H}_{2} \mathrm{O}\right)\right]$ with $\mathrm{Ln}(\mathrm{III})=\mathrm{Er}$ and $\mathrm{Yb}$ have a single supramolecular contact type $\pi-\pi$, which is also through the TPY ligands, aromatic ring containing the $\mathrm{N} 1$ atom of the reference molecule with the ring containing the nitrogen N3 of the neighboring molecule (Supplementary Materials, Figure S1).

\subsubsection{Structural Discussion}

The key to obtaining the structural types I and II for the described compounds by using the same synthetic method is the contraction of the ionic radius within the series of the lanthanide elements. As described, for the $\mathrm{Eu}(\mathrm{III})$ ion, with the largest ionic radius, the nona-coordinate coordination sphere is due to the coordination of three carboxylate ligands 9-anthc, two in chelating mode and one in monodentate mode, and for the coordination of a DMF molecule. For the $\mathrm{Tb}(\mathrm{III}), \mathrm{Dy}(\mathrm{III}), \mathrm{Er}(\mathrm{III})$, and $\mathrm{Yb}(\mathrm{III})$ ions, the compounds have been obtained with an octa-coordinate environment since the decrease in ionic radius causes two of the three 9 -anthc anions to be coordinated in monodentate mode and the last to be coordinated in chelating mode. This structural change is also accompanied by the coordination of a molecule of water instead of a DMF molecule.

\subsection{Magnetic Properties}

\subsection{1. dc Magnetic Studies}

Magnetic susceptibility $\left(\chi_{M}\right)$ data on polycrystalline powder samples of $\mathbf{1 E u}-\mathbf{5} \mathbf{Y b}$ were collected under fields of $3000 \mathrm{G}(300-30 \mathrm{~K})$ and $200 \mathrm{G}$ approximately (30-2 K). The data are represented as $\chi_{M} \mathrm{~T}$ vs. $\mathrm{T}$ plot in Figure $5 \mathrm{a}$.

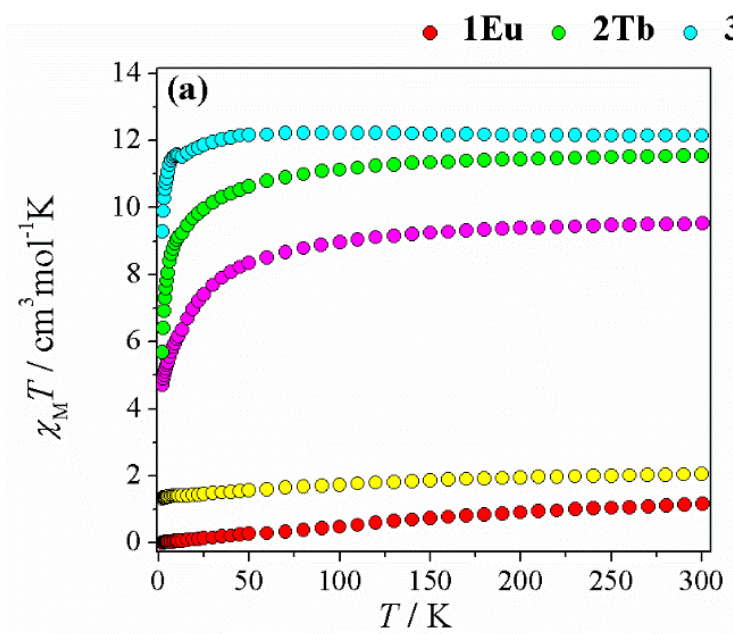

\section{Dy $\bullet 4 \mathrm{Er} \circ 5 \mathrm{Yb}$}

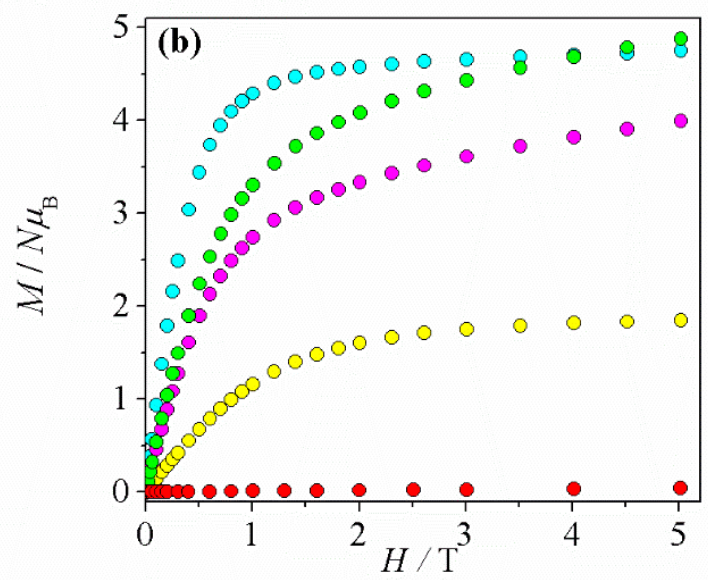

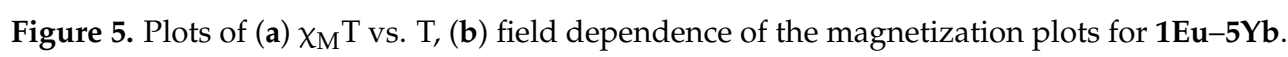

At $300 \mathrm{~K}$, the $\chi_{\mathrm{M}} \mathrm{T}$ values for compounds $1 \mathrm{Eu}-\mathbf{5} \mathbf{Y b}$ are 1.16, 11.55, 12.15, 9.52, and $2.05 \mathrm{~cm}^{3} \mathrm{~mol}^{-1} \mathrm{~K}$, respectively. These data are in good agreement with the expected room temperature values for the corresponding Ln(III) centers [53]. In the case of the 1Eu compound, the non-zero value of $\chi_{M} T$ reveals the presence of excited states that are very close in energy to the fundamental one [54]. For compounds $2 \mathrm{~Tb}$ and $4 \mathrm{Er}$, the $\chi_{\mathrm{M}} \mathrm{T}$ values remain practically constant as the samples are cooled to $\mathrm{T} \approx 150 \mathrm{~K}$. Below this temperature, 
the susceptibilities gradually decrease to values of $\chi_{M} \mathrm{~T}=9.12 \mathrm{~cm}^{3} \mathrm{~mol}^{-1} \mathrm{Ka} \mathrm{T}=11 \mathrm{~K}$ for $2 \mathrm{~Tb}$ and $\chi_{\mathrm{M}} \mathrm{T}=7.68 \mathrm{~cm}^{3} \mathrm{~mol}^{-1} \mathrm{~K}$ a T $=30 \mathrm{~K}$ for $4 \mathrm{Er}$. From these temperatures, the fall of the $\chi_{\mathrm{M}} \mathrm{T}$ values accelerates to reach minimum values equal to $5.69 \mathrm{~cm}^{3} \mathrm{~mol}^{-1} \mathrm{~K}$ for $2 \mathrm{~Tb}$ and $4.70 \mathrm{~cm}^{3} \mathrm{~mol}^{-1} \mathrm{~K}$ for $4 \mathrm{Er}$ at $\mathrm{T}=2 \mathrm{~K}$. For the $3 \mathrm{Dy}$ complex, it is observed that the $\chi_{\mathrm{M}}^{\mathrm{T}}$ values are practically constant when decreasing the temperature. From $\mathrm{T}=8 \mathrm{~K}$, the $\chi_{\mathrm{M}} \mathrm{T}$ values decrease quickly to $\chi_{\mathrm{M}} \mathrm{T}=9.28 \mathrm{~cm}^{3} \mathrm{~mol}^{-1} \mathrm{~K}$ at $2 \mathrm{~K}$.

Magnetization measurements at $2 \mathrm{~K}$ were also performed for complexes 1Eu-5Yb and are depicted in Figure 5b. The magnetization saturation under an applied field of $5 \mathrm{~T}$ is only observed in compounds $3 \mathrm{Dy}$ and $\mathbf{5 Y b}$, with $\mathrm{M}$ values equal to 4.75 and $1.85 N \mu_{B}$, respectively.

\subsection{2. ac Magnetic Studies}

Magnetic susceptibility measurements were performed on compounds $2 \mathbf{T b}-5 \mathbf{Y b}$ at a $4 \mathrm{G}$ ac field oscillating between 10 and $1488 \mathrm{~Hz}$. Under zero $d c$ magnetic field, no maxima for the in-phase $\left(\chi_{M}{ }^{\prime}\right)$ and out-of-phase $\left(\chi_{M}{ }^{\prime \prime}\right)$ susceptibility components were observed for any of the compounds, which was probably due to an important quantum tunneling of the magnetization (QTM) process present in these systems. To suppress the QTM relaxation process, an optimal external $d c$ field of $1000 \mathrm{G}$ was applied for the complexes $\mathbf{2} \mathbf{T b} \mathbf{- 5} \mathbf{Y b}$ after checking with low fields and basing on recent works reported by the authors [41-43]. Then, slow relaxation of the magnetization was revealed (Figure 6 and Supplementary Materials, Figure S2) for the compounds 3Dy-5Yb $[55,56]$.
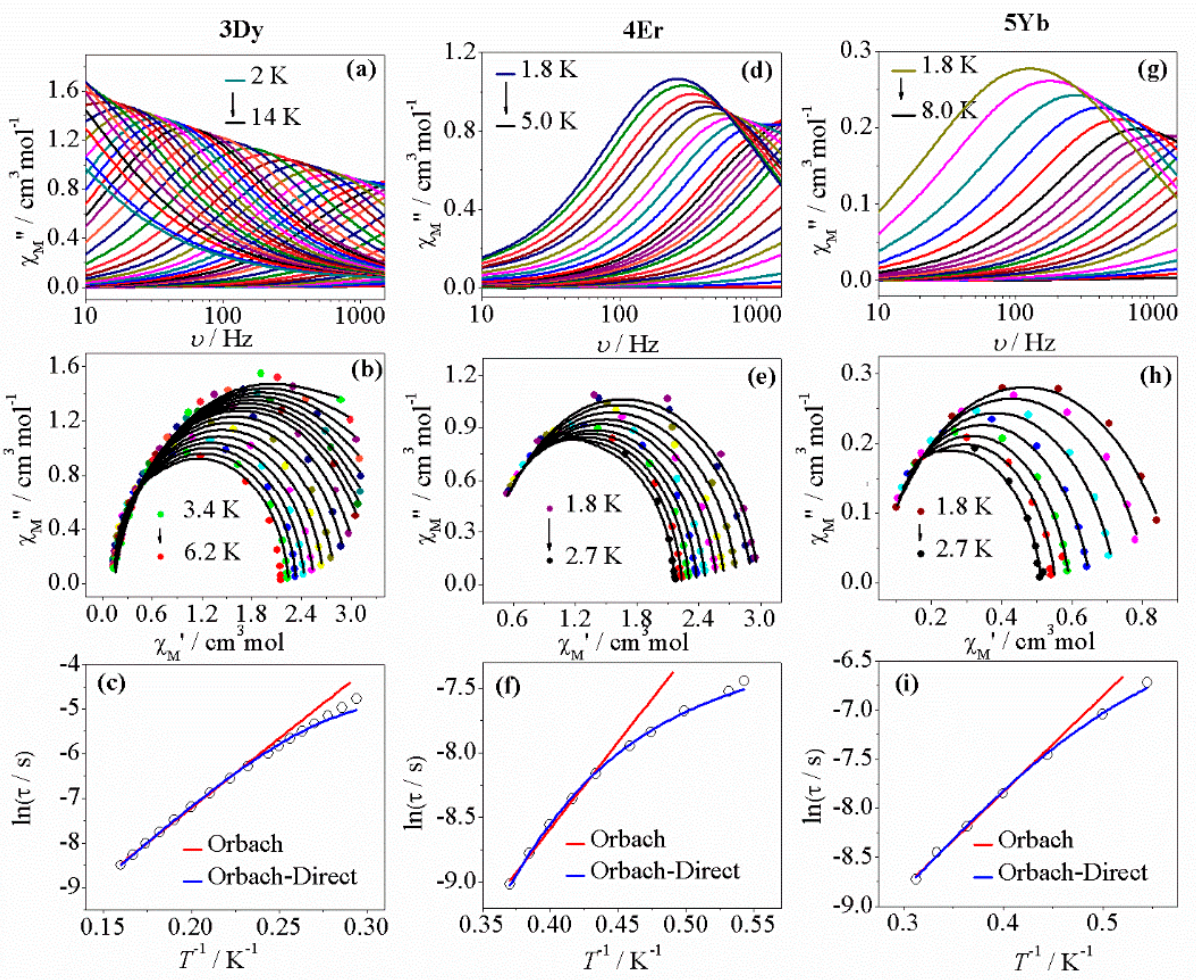

Figure 6. Plot of the ac susceptibility vs. frequency (out of phase susceptibility) for (a) 3Dy, (d) $4 \mathrm{Er}$, and (g) 5Yb; Cole-Cole plots of (b) 3Dy, (e) 4Er, and (h) 5Yb; Magnetization relaxation time, $\ln (\tau)$ vs. $\mathrm{T}^{-1}$ for (c) $3 \mathrm{Dy}$, (f) $4 \mathrm{Er}$, and (i) $5 \mathrm{Yb}$. Red and blue lines represent the fitting using the Arrhenius equation and combination of direct relaxation processes (see text).

For $\mathbf{2 T b}$, even under applied $d c$ fields up to $4000 \mathrm{G}$, no frequency or thermal dependency of $\chi_{M}{ }^{\prime}$ and/or $\chi_{M}{ }^{\prime \prime}$ were observed.

The ac magnetic susceptibility of compound 3Dy has been measured between 2 and 14 K. Figure 6a shows the out-of-phase component of the susceptibility $\left(\chi_{M}{ }^{\prime \prime}\right)$ vs. the 
frequency of the $a c$ field, with maxima for temperatures below $6.4 \mathrm{~K}$. The curves measured at temperatures between 6.2 and $3.4 \mathrm{~K}$ have been adjusted to the generalized Debye equation [57]. The corresponding Cole-Cole diagrams (Figure 6b) show slightly elongated semi-circular shapes, with $\alpha$ values between 0.13 and 0.06 . The low distribution of the relaxation times (Figure $6 \mathrm{c}$ from the Supplementary Materials, Table S4) indicates the presence of a single relaxation process. The fitting of the thermal dependence of $\tau$ with the Arrhenius law (Orbach relaxation mechanism) for temperatures higher than $4.5 \mathrm{~K}$ reveals values of $\tau_{0}=1.43 \times 10^{-6} \mathrm{~s}$ and $U_{\text {eff }}=21.7 \mathrm{~cm}^{-1}$. To fit the values throughout the range of temperatures, equation (Equation (1) was used, which also takes into account a direct relaxation. The obtained parameters were $\tau_{0}=8.47 \times 10^{-7} \mathrm{~s}, \mathrm{U}_{\text {eff }}=24.0 \mathrm{~cm}^{-1}$, and $\mathrm{A}=30 \mathrm{~K}^{-1} \mathrm{~s}^{-1}$.

$$
\tau^{-1}=\tau_{0}^{-1}\left[\exp \left(-U_{\mathrm{eff}} / k_{\mathrm{B}} T\right)\right]+A T
$$

For compound 4Er, the representation of $\chi_{\mathrm{M}}{ }^{\prime \prime}$ as a function of the frequency between temperatures of 5.0 and $1.8 \mathrm{~K}$ shows maxima for temperatures below $2.7 \mathrm{~K}$ (Figure $6 \mathrm{~d}$ ). The fitting of the Cole-Cole diagrams (Figure 6e) shows a narrow distribution of relaxation times with $\alpha$ values between 0.10 and 0.05 (from the Supplementary Materials, Table S5). The relaxation time follows a linear dependence at temperatures above $2.3 \mathrm{~K}$ and can be fitted according to the Arrhenius law. The parameters obtained were $\tau_{0}=8.68 \times 10^{-7} \mathrm{~s}$ and $U_{\text {eff }}=9.33 \mathrm{~cm}^{-1}$ (Figure $6 \mathrm{f}$ ). On the other hand, the data can be fitted throughout all the range of temperatures, taking into account Orbach and direct relaxation processes (Figure 6f). The parameters obtained from this second fitting are $\tau_{0}=4.67 \times 10^{-8} \mathrm{~s}$, $\mathrm{U}_{\mathrm{eff}}=15.4 \mathrm{~cm}^{-1}$, and $\mathrm{A}=903 \mathrm{~K}^{-1} \mathrm{~s}^{-1}$.

Compost $\mathbf{5 Y b}$ shows a maxima of $\chi_{\mathrm{M}}{ }^{\prime \prime}$ frequency dependents for temperatures lower than $2.7 \mathrm{~K}$ (Figure $6 \mathrm{~g}$ ). The Cole-Cole plots for temperatures between 2.7 and $1.8 \mathrm{~K}$ (Figure 6h) have a semi-circular shape. The fitting with the generalized Debye model indicates a narrow distribution of the relaxation times (from the Supplementary Materials, Table S6) with values of $\alpha$ between 0.12 and 0.24 . Figure $6 \mathbf{i}$ shows the thermal dependence of the relaxation times. For temperatures between 3.2 and $2.5 \mathrm{~K}$, the $\tau$ values can be modeled considering an Orbach relaxation mechanism with fitting parameters of $\tau_{0}=7.94 \times 10^{-6} \mathrm{~s}$ and $U_{\text {eff }}=6.79 \mathrm{~cm}^{-1}$. At temperatures below $2.5 \mathrm{~K}$, the values are deviated from linearity, but they can be fitted considering a relaxation of the magnetization by Orbach and direct processes. The parameter obtained are $\tau_{0}=4.16 \times 10^{-6} \mathrm{~s}, \mathrm{U}_{\text {eff }}=8.6 \mathrm{~cm}^{-1}$, and $\mathrm{A}=323 \mathrm{~K}^{-1} \mathrm{~s}^{-1}$.

\subsection{Photoluminescence Properties}

The emission properties of $\mathbf{1 E u}-\mathbf{5} \mathbf{Y b}$ were studied in solid state at r.t. and $77 \mathrm{~K}$.

\subsubsection{Visible Emission}

When compound 1Eu is excited at $\lambda_{\mathrm{ex}}=319 \mathrm{~nm}$, the resulting emission spectrum shows the characteristic $\mathrm{Eu}(\mathrm{III})$ transitions centered at $578 \mathrm{~nm}\left({ }^{5} \mathrm{D}_{0} \rightarrow{ }^{7} \mathrm{~F}_{0}\right), 591 \mathrm{~nm}$ $\left({ }^{5} \mathrm{D}_{0} \rightarrow{ }^{7} \mathrm{~F}_{1}\right), 616 \mathrm{~nm}\left({ }^{5} \mathrm{D}_{0} \rightarrow{ }^{7} \mathrm{~F}_{2}\right)$, and $692 \mathrm{~nm}\left({ }^{5} \mathrm{D}_{0} \rightarrow{ }^{7} \mathrm{~F}_{4}\right)$, as well as the residual emission of the 9 -anthc ligand as a broad band centered at $470 \mathrm{~nm}$ (Figure 7a). Meanwhile, the emission spectra of compounds 2Tb and 3Dy (Supplementary Materials, Figure S3) only show a broad band between 400 and $500 \mathrm{~nm}$ that corresponds to the 9 -anthc ligand. This may be because there is a water molecule directly bonded to the lanthanide atom, which normally quenches the luminescence of such metals. 

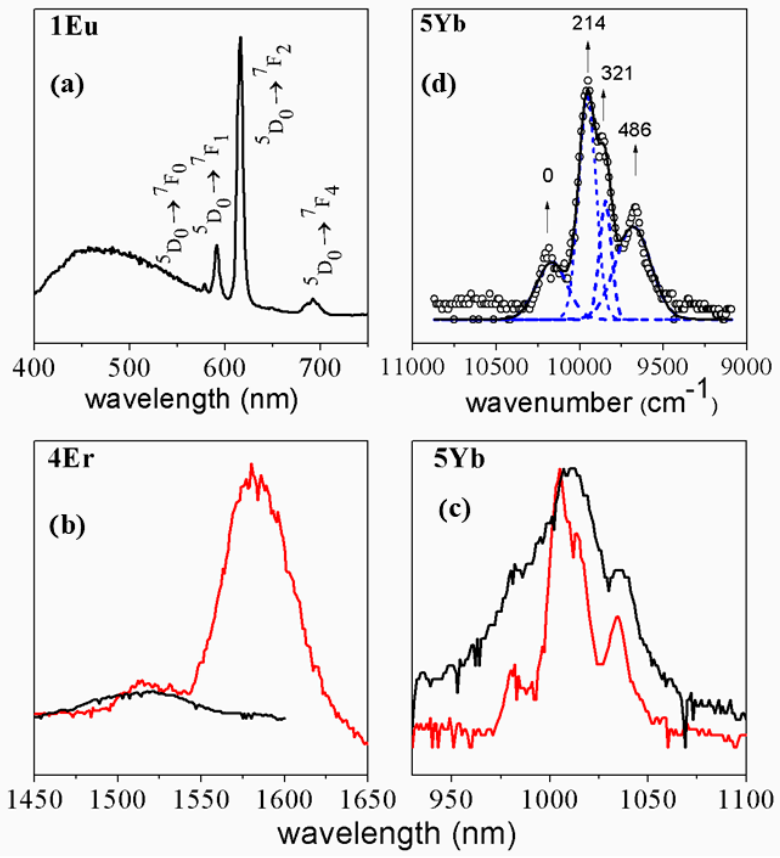

Figure 7. (a) Emission spectra at r.t. at $\lambda_{\mathrm{ex}}=350 \mathrm{~nm}$ in solid state of $\mathbf{1 E u} ;(\mathbf{b}, \mathbf{c})$ Emission spectra of $4 \mathrm{Er}$ and $5 \mathrm{Yb}$ at r.t (black spectra) and $77 \mathrm{~K}$ (red spectra) at $\lambda_{\mathrm{ex}}=360 \mathrm{~nm}$; (d) Gaussian deconvolution of the emission spectrum of $\mathbf{5 Y b}$, circles: Experimental spectrum, dashed lines: Gaussian deconvolutions, bold line: summed spectrum. Energy of the Stark sublevels.

\subsubsection{NIR Emission}

Complex $4 \mathrm{Er}$ shows a principal peak corresponding to the ${ }^{4} \mathrm{I}_{13 / 2} \rightarrow{ }^{4} \mathrm{I}_{15 / 2}$ transition with a maximum at $1580 \mathrm{~nm}$ (Figure $7 \mathrm{~b}$ ). Decreasing the temperature to $77 \mathrm{~K}$ does not permit us to increase sufficiently the resolution to have access to the crystal field splitting. Compound $4 \mathrm{Er}$, when measured at room temperature and at $77 \mathrm{~K}$ under an excitation wavelength of $360 \mathrm{~nm}$, shows broad peaks of residual emission of the ligands between 390 and $550 \mathrm{~nm}$, in the absorption range of the 9-anthc ligand (Figure S4). As can be seen in Figure $7 \mathrm{~b}$, under this same excitation energy and at $\mathrm{T}=77 \mathrm{~K}$, the compound also emits in the area of the near IR, with a maximum of $1580 \mathrm{~nm}$, which correspond to the transition ${ }^{4} \mathrm{I}_{13 / 2} \rightarrow{ }^{4} \mathrm{I}_{15 / 2}$.

Complex $5 \mathrm{Yb}$ shows the characteristic $\mathrm{Yb}(\mathrm{III})$ transition emission profile, with the principal transition ${ }^{2} \mathrm{~F}_{5 / 2} \rightarrow{ }^{2} \mathrm{~F}_{7 / 2}$ at $1005 \mathrm{~nm}$ (Figure $7 \mathrm{c}$, black spectrum). When decreasing the temperature to $77 \mathrm{~K}$ (Figure $7 \mathrm{c}$, red line), the emission band splits into four bands, with the maxima at 980,1005, 1014, and $1035 \mathrm{~nm}$, which correspond to the four expected Stark levels for a $J=7 / 2$ in low symmetry $[56,58]$. This transition offers us information of the crystal field energy diagram of the ytterbium ion in complex $5 \mathbf{Y b}$ and permits us to estimate the energy between the ground and the first excited $\mathrm{m}_{J}$ states of the fundamental ${ }^{2} \mathrm{~F}_{7 / 2}$ level of about $210 \mathrm{~cm}^{-1}$ (Figure 7d). The difference between this value and the effective energy barrier value obtained from the Arrhenius fit of the $a c$ data $\left(\approx 7.0 \mathrm{~cm}^{-1}\right)$ confirms that relaxation of the magnetization takes place by direct and/or Raman processes instead of only the Orbach one [59].

\section{Experimental Section}

\subsection{Starting Materials}

$\mathrm{Ln}\left(\mathrm{NO}_{3}\right)_{3} \cdot \mathrm{xH}_{2} \mathrm{O}$ salts, 9-anthracenecarboxylic acid (9-Hanthc), 2,2':6,2'-terpyridine (TPY), methanol, and N,N-dimethylformamide were obtained from Sigma Aldrich and used without further purification. 


\subsection{General Syntheses}

Compounds $1 \mathbf{E u}-\mathbf{5} \mathbf{Y b}$ have been synthetized by following the same experimental procedure. To a solution consisting of $1.5 \mathrm{mmol}$ 9-Hanthc and $0.3 \mathrm{mmol}$ TPY in $15 \mathrm{~mL}$ of $\mathrm{MeOH}$, a solution of $10 \mathrm{~mL}$ DMF containing $0.25 \mathrm{mmol}$ of $\mathrm{Ln}\left(\mathrm{NO}_{3}\right)_{3} \cdot \mathrm{xH}_{2} \mathrm{O}$ is added $(\operatorname{Ln}(\mathrm{III})=\mathrm{Eu}(\mathbf{1 E u}), \mathrm{Tb}(2 \mathrm{~Tb}), \mathrm{Dy}(3 \mathrm{Dy}), \mathrm{Er}(4 \mathrm{Er})$, and $\mathrm{Yb}(5 \mathrm{Yb})$. In all the cases, slow evaporation of the methanol/dimethylformamide solution of the product gave prismshaped yellow monocrystals suitable for $\mathrm{X}$-ray determination.

Data for 1Eu: Selected IR bands (KBr pellet, $\left.\mathrm{cm}^{-1}\right)$ : $3418\left(\mathrm{~m}, \mathrm{vH}_{2} \mathrm{O}(\mathrm{O}-\mathrm{H})\right), 1650$ (s, vas(COO- $\left.)^{\mathrm{a}}\right), 1597\left(\mathrm{vs}, \operatorname{vas}(\mathrm{COO}-)^{\mathrm{b}}\right), 1574(\mathrm{vs}, \mathrm{v}(\mathrm{C}=\mathrm{N})), 1436\left(\mathrm{~m}, \mathrm{vs}(\mathrm{COO}-)^{\mathrm{b}}\right), 1386(\mathrm{~s}$, us $\left.(\mathrm{COO}-)^{\mathrm{a}}\right)$. $\mathrm{C}_{63} \mathrm{H}_{47} \mathrm{EuN}_{4} \mathrm{O}$ (1140.01): Calc. (\%) C 66.37, H 4.15, N 4.91; Found C 67.1, H 4.5, N 4.8 .

Data for 2Tb: Selected IR bands $\left(\mathrm{KBr}\right.$ pellet, $\left.\mathrm{cm}^{-1}\right)$ : $3440\left(\mathrm{~s}, v \mathrm{H}_{2} \mathrm{O}(\mathrm{O}-\mathrm{H})\right), 1664(\mathrm{~m}$, vas(COO- $\left.)^{\mathrm{a}}\right), 1598\left(\mathrm{~s}, \operatorname{vas}(\mathrm{COO}-)^{\mathrm{b}}\right), 1556(\mathrm{~s}, v(\mathrm{C}=\mathrm{N})), 1443\left(\mathrm{~m}, \mathrm{vs}(\mathrm{COO}-)^{\mathrm{b}}\right), 1385(\mathrm{~m}$, us $\left.(\mathrm{COO}-)^{\mathrm{a}}\right)$. $\mathrm{C}_{63} \mathrm{H}_{49} \mathrm{~N}_{4} \mathrm{O}_{9} \mathrm{~Tb}$ (1164.99): Calc. (\%) C 64.95, H 4.24, N 4.81; Found C 64.9, H 4.6, N 4.8.

Data for 3Dy: Selected IR bands (KBr pellet, $\left.\mathrm{cm}^{-1}\right)$ : $3444\left(\mathrm{~m}, \mathrm{vH}_{2} \mathrm{O}(\mathrm{O}-\mathrm{H})\right), 1659$ (s, vas(COO- $\left.)^{\mathrm{a}}\right), 1596\left(\mathrm{~s}, \operatorname{vas}(\mathrm{COO}-)^{\mathrm{b}}\right), 1559(\mathrm{~m}, \mathrm{v}(\mathrm{C}=\mathrm{N})), 1445\left(\mathrm{~m}, \mathrm{vs}(\mathrm{COO}-)^{\mathrm{b}}\right), 1385(\mathrm{~m}$, vs $\left.(\mathrm{COO}-)^{\mathrm{a}}\right)$. $\mathrm{C}_{63} \mathrm{H}_{49} \mathrm{DyN}_{4} \mathrm{O}_{9}$ (1168.56) Calc. (\%) C 64.75, H 4.23, N 4.79; Found C 64.5, $\mathrm{H} 4.3, \mathrm{~N} 4.7$.

Data for 4Er: Selected IR bands (KBr pellet, $\left.\mathrm{cm}^{-1}\right)$ : $3442\left(\mathrm{~s}, v \mathrm{H}_{2} \mathrm{O}(\mathrm{O}-\mathrm{H})\right), 1675$ (s, vas $\left.(\mathrm{COO}-)^{\mathrm{a}}\right), 1598\left(\mathrm{vs}, \operatorname{vas}(\mathrm{COO}-)^{\mathrm{b}}\right), 1535(\mathrm{~s}, v(\mathrm{C}=\mathrm{N})), 1448\left(\mathrm{~s}\right.$, vs $\left.(\mathrm{COO}-)^{\mathrm{b}}\right), 1385(\mathrm{~m}$, us $\left.(\mathrm{COO}-)^{\mathrm{a}}\right)$. $\mathrm{C}_{63} \mathrm{H}_{49} \mathrm{ErN}_{4} \mathrm{O}_{9}$ (1173.32): Calc. (\%) C 64.49, H 4.21, N 4.77; Found C 64.3, H 4.3, N 4.9.

Data for $5 \mathrm{Yb}$ : Selected IR bands ( $\mathrm{KBr}$ pellet, $\left.\mathrm{cm}^{-1}\right)$ : $3455\left(\mathrm{~m}, v \mathrm{H}_{2} \mathrm{O}(\mathrm{O}-\mathrm{H})\right.$ ), 1658 (vs, vas $\left.(\mathrm{COO}-)^{\mathrm{a}}\right), 1596\left(\mathrm{vs}, \operatorname{vas}(\mathrm{COO}-)^{\mathrm{b}}\right), 1555(\mathrm{~s}, v(\mathrm{C}=\mathrm{N})), 1452\left(\mathrm{~s}\right.$, vs $\left.(\mathrm{COO}-)^{\mathrm{b}}\right), 1384(\mathrm{~m}$, us $\left.(\mathrm{COO}-)^{\mathrm{a}}\right) \cdot \mathrm{C}_{63} \mathrm{H}_{49} \mathrm{~N}_{4} \mathrm{O}_{9} \mathrm{Yb}(1179.10)$ : Calc. (\%) C 64.17, H 4.19, N 4.75; Found C 63.9, H 4.4, N 4.8 .

${ }^{(a)}$ is 9 -anthcencarboxylate in monodentate coordination mode and $\left({ }^{b}\right)$ is 9 -anthcencarboxylate in chelate coordination mode.

\subsection{Physical Measurements}

Elemental analyses of the compounds were done at the Serveis Científics i Tecnològics of the Universitat de Barcelona.

Infrared spectra (4000-400 $\mathrm{cm}^{-1}$ ) were registered from $\mathrm{KBr}$ pellets on a Perkin-Elmer 380-B spectrophotometer.

Luminescence spectra were registered on a Horiba Jobin Yvon SPEX Nanolog fluorescence spectrophotometer at rt. and at $77 \mathrm{~K}$.

Magnetic measurements were done on polycrystalline samples in a Quantum Design MPMS-XL SQUID magnetometer at the Unitat de Mesures Magnètiques (CCiTUB) of the Universitat de Barcelona. To estimate the diamagnetic corrections, Pascal's constants were used and subtracted from the experimental susceptibilities to give the corrected molar magnetic susceptibilities.

\subsection{X-ray Crystallography}

Crystal data, conditions retained for the intensity data collection, and some features of the structure refinements for $\mathbf{1 E u}-\mathbf{5} \mathbf{Y b}$ are summarized in Table 2. Crystals of $\mathbf{1 E u}-\mathbf{5} \mathbf{Y b}$ were selected and mounted in air on a D8VENTURE (Bruker) diffractometer with a CMOS detector. All the structures were refined by the least-squares method. Intensities were collected with a multilayer monochromated $\mathrm{Mo}-\mathrm{K} \alpha$ radiation. Lorentz polarization and absorption corrections were made in all the compounds. The structures were solved by direct methods, using the SHELXS-97 software [60] and refined by the full-matrix leastsquares method, using the SHELXL software [61]. The non-H atoms were located in successive difference Fourier syntheses and refined with anisotropic thermal parameters 
on $F^{2}$. In the case of $\mathrm{H}$ atoms, isotropic temperature factors have been assigned as 1.2 or 1.5 times of the respective parent.

CCDC 2095083 (for 1Eu), 2095084 (for 2Tb), 2095085 (for 3Dy), 2095081 (for 4Er), and 2095082 (for $\mathbf{5} \mathbf{Y b}$ ) contain the supplementary crystallographic data for this paper. These data can be obtained free of charge via http://www.ccdc.cam.ac.uk/conts/retrieving.html, accessed on 7 July 2021.

\section{Conclusions}

Here, we have presented the structural, magnetic, and luminescence studies of new five mononuclear $\mathrm{Ln}$ (III) complexes by employing 9-anthracenecarboxylic acid (9-Hanthc) and $2,2^{\prime}: 6,2^{\prime \prime}$-terpyridine ligands. We have used a straightforward room-temperature synthetic procedure, and the viability of the experimental processes adopted to obtain low-nuclear coordination compounds with Ln(III) has been corroborated.

Structurally, the decrease on the ionic radii across the $4 f$ row is translated into two different structures obtained with formulae $\left[\mathrm{Eu}(9 \text {-anthc) })_{3}(\mathrm{TPY})(\mathrm{DMF})\right] \cdot \mathrm{H}_{2} \mathrm{O}(\mathbf{1 E u})$ where $\mathrm{Eu}(\mathrm{III})$ is ennea-coordinated or [ $\left.\mathrm{Ln}(9 \text {-anthc })_{3}(\mathrm{TPY})\left(\mathrm{H}_{2} \mathrm{O}\right)\right] \cdot \mathrm{H}_{2} \mathrm{O} \cdot \mathrm{DMF}(\mathrm{Ln}=\mathrm{Tb}(\mathbf{2} \mathbf{T b})$, Dy (3Dy), Er (4Er), and $\mathrm{Yb}(5 \mathbf{Y b})$ ) where $\mathrm{Ln}(\mathrm{III})$ are octa-coordinated.

From the same stoichiometric relationship between Ln (III) salt, 9-antracencarboxylic acid, the secondary ligand $2,2^{\prime}: 6^{\prime}, 2^{\prime \prime}$-terpyridine ( $3 \mathrm{~N}$-donors atoms), favors the production of mononuclear structures while the ligands 2,2'-bipyridine or 1,10-phenanthroline (2 Ndonors atoms) favor the dinuclear structures.

To the best of our knowledge, the complexes $1 \mathbf{E u}-\mathbf{5} \mathbf{Y b}$ reported in this work are the first examples of mononucleares complexes of lanthanide(III) in combination with secondary organic ligands.

Dynamic magnetic measurements indicate field-induced SMM behavior for complexes $3 \mathrm{Dy}, 4 \mathrm{Er}$, and $5 \mathrm{Yb}$.

Not all the compounds discussed in this work show the $f-f$ emission luminescence. $\mathrm{The} \mathrm{Eu}(\mathrm{III})$ (1Eu), $\mathrm{Tb}(\mathrm{III})(\mathbf{2 T b})$, and $\mathrm{Dy}(\mathrm{III})$ (3Dy) compounds emit in the visible range, while the $\mathrm{Er}(\mathrm{III})(4 \mathrm{Er})$ and $\mathrm{Yb}(\mathrm{III})(5 \mathrm{Yb})$ compounds emit in the NIR range.

Thus, compounds $4 \mathrm{Er}$ and $\mathbf{5 Y b}$ present both field-induced SMM and luminescent behaviors; therefore, they can be considered as multifunctional compounds with possible potential biomedical applications.

The results reported certainly will attract the interest of scientists working in the area of multifunctional lanthanide compounds.

More and further investigations in this area with other lanthanide metal ions and chiral organic ligands could be very interesting. Such investigations are under development in our laboratories with promising results.

Supplementary Materials: The following are available online at https:/ /www.mdpi.com/article/ 10.3390/magnetochemistry7090124/s1, Figure S1: Supramolecular arrangement representation in (a) $4 \mathrm{Er}$, (b) $5 \mathrm{Yb} . \pi-\pi$ stacking interactions are indicated in blue, Figure $S 2: \chi_{M}{ }^{\prime}$ and $\chi_{M}{ }^{\prime \prime} v s$. T plots for compounds 3Dy-5Yb, Figure S3: Emission spectra for $\mathbf{2} \mathbf{T b}$ and $3 \mathrm{Dy}$ at rt., Figure S4: Emission spectra for $4 \mathrm{Er}$ at r.t. (back line) and at $77 \mathrm{~K}$ (red line), Table S1: Continuous shape measures (CShMs) using SHAPE software for $\mathbf{2} \mathbf{T b}-\mathbf{5} \mathbf{Y b}$, Table S2: Hydrogen bonds distances ( $\mathrm{d}$; $\mathrm{D}=$ donor atom, $\mathrm{A}=$ acceptor atom) and angles of $\mathbf{1 E u}-\mathbf{5} \mathbf{Y b}$, Table S3: Supramolecular $\pi-\pi$ stacking interactions for $\mathbf{1 E u}-\mathbf{5} \mathbf{Y b}$, Tables S4-S6: Relaxation parameters values for the best fit of $\chi_{M}{ }^{\prime \prime}$ and $\chi_{M}{ }^{\prime}$ vs. frequency using generalized Debye model for $3 \mathrm{Dy}-\mathbf{5} \mathbf{Y b}$.

Author Contributions: Synthesis and characterization of the compounds, O.P. and B.C.; performance of the photoluminescence measurements and analysis of the results of magnetic studies for all compounds, B.C. and S.S.; contribution on the writing-original draft preparation, B.C., S.S. and R.V.; conceptualization, R.V.; performance of single-crystal X-ray diffraction experiments and refinement, M.F.-B.; supervision and preparation-editing of the final version of the manuscript, M.S.E.F. All authors have read and agreed to the published version of the manuscript. 
Funding: This work was supported by the Spanish Ministry of Science and Innovation (MICINN) Project PGC2018-094031-B-100.

Data Availability Statement: The data presented in this study are available in this article and in the Supplementary Materials.

Conflicts of Interest: There is no conflict to declare.

\section{References}

1. Gatteschi, D.; Sessoli, R.; Villain, J. Molecular Nanomagnets; Oxford University Press: Oxford, UK, 2007; Volume 5, ISBN 9780191718298.

2. Bogani, L.; Wernsdorfer, W. Molecular spintronics using single-molecule magnets. Nat. Mater. 2008, 7, 179-186. [CrossRef] [PubMed]

3. Mannini, M.; Pineider, F.; Sainctavit, P.; Danieli, C.; Otero, E.; Sciancalepore, C.; Talarico, A.M.; Arrio, M.-A.; Cornia, A.; Gatteschi, D.; et al. Magnetic memory of a single-molecule quantum magnet wired to a gold surface. Nat. Mater. 2009, 8, 194-197. [CrossRef]

4. Leuenberger, M.N.; Loss, D. Quantum computing in molecular magnets. Nature 2001, 410, 789-793. [CrossRef] [PubMed]

5. Lehmann, J.; Gaita-Arino, A.; Coronado, E.; Loss, D. Spin qubits with electrically gated polyoxometalate molecules. Nat. Nanotechnol. 2007, 2, 312-317. [CrossRef] [PubMed]

6. Ganzhorn, M.; Klyatskaya, S.; Ruben, M.; Wernsdorfer, W. Strong spin-phonon coupling between a single-molecule magnet and a carbon nanotube nanoelectromechanical system. Nat. Nanotechnol. 2013, 8, 165-169. [CrossRef]

7. Long, J.; Guari, Y.; Ferreira, R.A.S.; Carlos, L.D.; Larionova, J. Recent advances in luminescent lanthanide based Single-Molecule Magnets. Coord. Chem. Rev. 2018, 363, 57-70. [CrossRef]

8. Pointillart, F.; le Guennic, B.; Cador, O.; Maury, O.; Ouahab, L. Lanthanide Ion and Tetrathiafulvalene-Based Ligand as a "Magic" Couple toward Luminescence, Single Molecule Magnets, and Magnetostructural Correlations. Acc. Chem. Res. 2015, 48, $2834-2842$. [CrossRef]

9. Bi, Y.; Chen, C.; Zhao, Y.-F.; Zhang, Y.-Q.; Jiang, S.-D.; Wang, B.-W.; Han, J.-B.; Sun, J.-L.; Bian, Z.-Q.; Wang, Z.-M.; et al. Thermostability and photoluminescence of Dy(III) single-molecule magnets under a magnetic field. Chem. Sci. 2016, 7, 5020-5031. [CrossRef]

10. Al Hareri, M.; Gavey, E.L.; Regier, J.; Ras Ali, Z.; Carlos, L.D.; Ferreira, R.A.S.; Pilkington, M. Encapsulation of a $\left[\mathrm{Dy}\left(\mathrm{OH}_{2}\right)_{8}\right]^{3+}$ cation: Magneto-optical and theoretical studies of a caged, emissive SMM. Chem. Commun. 2016, 52, 11335-11338. [CrossRef]

11. Li, Q.-W.; Liu, J.-L.; Jia, J.-H.; Chen, Y.-C.; Liu, J.; Wang, L.-F.; Tong, M.-L. “Half-sandwich” Yb III single-ion magnets with metallacrowns. Chem. Commun. 2015, 51, 10291-10294. [CrossRef] [PubMed]

12. Gavey, E.L.; Al Hareri, M.; Regier, J.; Carlos, L.D.; Ferreira, R.A.S.; Razavi, F.S.; Rawson, J.M.; Pilkington, M. Placing a crown on Dy III-A dual property Ln III crown ether complex displaying optical properties and SMM behaviour. J. Mater. Chem. C 2015, 3, 7738-7747. [CrossRef]

13. Soussi, K.; Jung, J.; Pointillart, F.; Le Guennic, B.; Lefeuvre, B.; Golhen, S.; Cador, O.; Guyot, Y.; Maury, O.; Ouahab, L. Magnetic and photo-physical investigations into Dy III and $\mathrm{Yb}$ III complexes involving tetrathiafulvalene ligand. Inorg. Chem. Front. 2015, 2, 1105-1117. [CrossRef]

14. Yi, X.; Bernot, K.; Le Corre, V.; Calvez, G.; Pointillart, F.; Cador, O.; Le Guennic, B.; Jung, J.; Maury, O.; Placide, V.; et al. Unraveling the Crystal Structure of Lanthanide-Murexide Complexes: Use of an Ancient Complexometry Indicator as a Near-InfraredEmitting Single-Ion Magnet. Chem. A Eur. J. 2014, 20, 1569-1576. [CrossRef]

15. Shintoyo, S.; Murakami, K.; Fujinami, T.; Matsumoto, N.; Mochida, N.; Ishida, T.; Sunatsuki, Y.; Watanabe, M.; Tsuchimoto, M.; Mrozinski, J.; et al. Crystal Field Splitting of the Ground State of Terbium(III) and Dysprosium(III) Complexes with a Triimidazolyl Tripod Ligand and an Acetate Determined by Magnetic Analysis and Luminescence. Inorg. Chem. 2014, 53, 10359-10369. [CrossRef]

16. Ren, M.; Bao, S.-S.; Ferreira, R.A.S.; Zheng, L.-M.; Carlos, L.D. A layered erbium phosphonate in pseudo-D5h symmetry exhibiting field-tunable magnetic relaxation and optical correlation. Chem. Commun. 2014, 50, 7621. [CrossRef] [PubMed]

17. Long, J.; Vallat, R.; Ferreira, R.A.S.; Carlos, L.D.; Almeida Paz, F.A.; Guari, Y.; Larionova, J. A bifunctional luminescent single-ion magnet: Towards correlation between luminescence studies and magnetic slow relaxation processes. Chem. Commun. 2012, 48, 9974. [CrossRef]

18. Cucinotta, G.; Perfetti, M.; Luzon, J.; Etienne, M.; Car, P.-E.; Caneschi, A.; Calvez, G.; Bernot, K.; Sessoli, R. Magnetic Anisotropy in a Dysprosium/DOTA Single-Molecule Magnet: Beyond Simple Magneto-Structural Correlations. Angew. Chem. Int. Ed. 2012, 51, 1606-1610. [CrossRef] [PubMed]

19. Pointillart, F.; Guennic, B.L.; Golhen, S.; Cador, O.; Maury, O.; Ouahab, L. A redox-active luminescent ytterbium based single molecule magnet. Chem. Commun. 2013, 49, 615-617. [CrossRef]

20. Chen, Y.-C.; Liu, J.-L.; Lan, Y.; Zhong, Z.-Q.; Mansikkamäki, A.; Ungur, L.; Li, Q.-W.; Jia, J.-H.; Chibotaru, L.F.; Han, J.-B.; et al. Dynamic Magnetic and Optical Insight into a High Performance Pentagonal Bipyramidal Dy III Single-Ion Magnet. Chem. A Eur. J. 2017, 23, 5708-5715. [CrossRef] 
21. Ruiz, J.; Lorusso, G.; Evangelisti, M.; Brechin, E.K.; Pope, S.J.A.; Colacio, E. Closely-Related $\mathrm{Zn}_{2}{ }_{2} \mathrm{Ln}^{\mathrm{III}}{ }_{2} \mathrm{Complexes}\left(\mathrm{Ln}^{\mathrm{III}}=\mathrm{Gd}\right.$, $\mathrm{Yb}$ ) with Either Magnetic Refrigerant or Luminescent Single-Molecule Magnet Properties. Inorg. Chem. 2014, 53, 3586-3594. [CrossRef] [PubMed]

22. Yamashita, K.; Miyazaki, R.; Kataoka, Y.; Nakanishi, T.; Hasegawa, Y.; Nakano, M.; Yamamura, T.; Kajiwara, T. A luminescent single-molecule magnet: Observation of magnetic anisotropy using emission as a probe. Dalton Trans. 2013, 42, 1987. [CrossRef] [PubMed]

23. Li, Q.-W.; Liu, J.-L.; Jia, J.-H.; Leng, J.-D.; Lin, W.-Q.; Chen, Y.-C.; Tong, M.-L. Fluorescent single-ion magnets: Molecular hybrid (HNEt3)[DyxYb1-x(bpyda)2] (x=0.135-1). Dalton Trans. 2013, 42, 11262. [CrossRef]

24. Boulon, M.-E.; Cucinotta, G.; Luzon, J.; Degl'Innocenti, C.; Perfetti, M.; Bernot, K.; Calvez, G.; Caneschi, A.; Sessoli, R. Magnetic Anisotropy and Spin-Parity Effect Along the Series of Lanthanide Complexes with DOTA. Angew. Chemie Int. Ed. 2013, 52, 350-354. [CrossRef]

25. Marin, R.; Brunet, G.; Murugesu, M. Shining New Light on Multifunctional Lanthanide Single-Molecule Magnets. Angew. Chem. Int. Ed. 2021, 60, 1728-1746. [CrossRef]

26. Bünzli, J.-C.G.; Piguet, C. Taking advantage of luminescent lanthanide ions. Chem. Soc. Rev. 2005, 34, 1048. [CrossRef] [PubMed]

27. Vleck, J.H.V. The Puzzle of Rare-earth Spectra in Solids. J. Phys. Chem. 1937, 41, 67-80. [CrossRef]

28. D'Aléo, A.; Pointillart, F.; Ouahab, L.; Andraud, C.; Maury, O. Charge transfer excited states sensitization of lanthanide emitting from the visible to the near-infra-red. Coord. Chem. Rev. 2012, 256, 1604-1620. [CrossRef]

29. So, S.; Mackenzie, J.I.; Shepherd, D.P.; Clarkson, W.A.; Betterton, J.G.; Gorton, E.K.; Terry, J.A.C. Intra-cavity side-pumped Ho:YAG laser. Opt. Express 2006, 14, 10481. [CrossRef]

30. Kuriki, K.; Koike, Y.; Okamoto, Y. Plastic Optical Fiber Lasers and Amplifiers Containing Lanthanide Complexes. Chem. Rev. 2002, 102, 2347-2356. [CrossRef]

31. Zang, F.X.; Hong, Z.R.; Li, W.L.; Li, M.T.; Sun, X.Y. $1.4 \mu \mathrm{m}$ band electroluminescence from organic light-emitting diodes based on thulium complexes. Appl. Phys. Lett. 2004, 84, 2679-2681. [CrossRef]

32. Feng, J.; Zhou, L.; Song, S.-Y.; Li, Z.-F.; Fan, W.-Q.; Sun, L.-N.; Yu, Y.-N.; Zhang, H.-J. A study on the near-infrared luminescent properties of xerogel materials doped with dysprosium complexes. Dalton Trans. 2009, 33, 6593-6598. [CrossRef] [PubMed]

33. Puntus, L.N.; Schenk, K.J.; Bünzli, J.-C.G. Intense Near-Infrared Luminescence of a Mesomorphic Ionic Liquid Doped with Lanthanide $\$ \beta \$$-Diketonate Ternary Complexes. Eur. J. Inorg. Chem. 2005, 2005, 4739-4744. [CrossRef]

34. Glover, P.B.; Bassett, A.P.; Nockemann, P.; Kariuki, B.M.; Van Deun, R.; Pikramenou, Z. Fully Fluorinated Imidodiphosphinate Shells for Visible- and NIR-Emitting Lanthanides: Hitherto Unexpected Effects of Sensitizer Fluorination on Lanthanide Emission Properties. Chem. A Eur. J. 2007, 13, 6308-6320. [CrossRef]

35. Leonard, J.P.; dos Santos, C.M.G.; Plush, S.E.; McCabe, T.; Gunnlaugsson, T. pH driven self-assembly of a ternary lanthanide luminescence complex: The sensing of anions using a $\beta$-diketonate-Eu(III) displacement assay. Chem. Commun. 2007, 2, 129-131. [CrossRef]

36. Binnemans, K.; Görller-Walrand, C. Lanthanide-Containing Liquid Crystals and Surfactants. Chem. Rev. 2002, 102, 2303-2346. [CrossRef] [PubMed]

37. Faulkner, S.; Pope, S.J.A.; Burton-Pye, B.P. Lanthanide Complexes for Luminescence Imaging Applications. Appl. Spectrosc. Rev. 2005, 40, 1-31. [CrossRef]

38. Yam, V.W.-W.; Lo, K.K.-W. Recent advances in utilization of transition metal complexes and lanthanides as diagnostic tools. Coord. Chem. Rev. 1999, 184, 157-240. [CrossRef]

39. De Sá, G.F.; Malta, O.L.; de Mello Donegá, C.; Simas, A.M.; Longo, R.L.; Santa-Cruz, P.A.; da Silva, E.F. Spectroscopic properties and design of highly luminescent lanthanide coordination complexes. Coord. Chem. Rev. 2000, 196, 165-195. [CrossRef]

40. Pietraszkieyvicz, M.; Karpiuk, J.; Rout, A.K. Lanthanide complexes of macrocyclic and macrobicyclic N-oxides; light-converting supramolecular devices. Pure Appl. Chem. 1993, 65, 563-566. [CrossRef]

41. Casanovas, B.; Font-Bardía, M.; Speed, S.; El Fallah, M.S.; Vicente, R. Field-Induced SMM and Visible/NIR-Luminescence Behaviour of Dinuclear Ln III Complexes with 2-Fluorobenzoate. Eur. J. Inorg. Chem. 2018, 2018, 1928-1937. [CrossRef]

42. Casanovas, B.; Speed, S.; Maury, O.; El Fallah, M.S.; Font-Bardía, M.; Vicente, R. Dinuclear Ln ${ }^{\mathrm{III}}$ Complexes with 9 Anthracenecarboxylate Showing Field-Induced SMM and Visible/NIR Luminescence. Eur. J. Inorg. Chem. 2018, 2018, 3859-3867. [CrossRef]

43. Casanovas, B.; Speed, S.; Vicente, R.; Font-Bardía, M. Sensitization of visible and NIR emitting lanthanide(III) ions in a series of dinuclear complexes of formula $\left[\mathrm{Ln}_{2}(\mu-2-\mathrm{FBz})_{2}(2-\mathrm{FBz})_{4}(\text { terpy })_{2}\right] \cdot 2(2-\mathrm{HFBz}) \cdot 2\left(\mathrm{H}_{2} \mathrm{O}\right)$. Polyhedron 2019, 173, 114113. [CrossRef]

44. Groom, C.R.; Bruno, I.J.; Lightfoot, M.P.; Ward, S.C. The Cambridge Structural Database. Acta Crystallogr. Sect. B Struct. Sci. Cryst. Eng. Mater. 2016, 72, 171-179. [CrossRef] [PubMed]

45. Utochnikova, V.V.; Kalyakina, A.S.; Bushmarinov, I.S.; Vashchenko, A.A.; Marciniak, L.; Kaczmarek, A.M.; Van Deun, R.; Bräse, S.; Kuzmina, N.P. Lanthanide 9-anthracenate: Solution processable emitters for efficient purely NIR emitting host-free OLEDs. J. Mater. Chem. C 2016, 4, 9848-9855. [CrossRef]

46. Liu, C.-S.; Guo, L.-Q.; Yan, L.-F.; Wang, J.-J. Tetrakis( $\mu$-anthracene-9-carboxylato)- $\kappa^{4} O: O^{\prime} ; \kappa^{3} O, O^{\prime}: O^{\prime} ; \kappa^{3} O: O, O^{\prime}$-bis[(anthracene-9carboxylato- $\left.\kappa^{2} O, \mathrm{O}^{\prime}\right)\left(1,10\right.$-phenanthroline- $\left.\mathrm{K}^{2} N, N^{\prime}\right)$ erbium(III)]: Effects of a noncoordinating anthracene ligand ring system on the final structure of a coordination complex. Acta Crystallogr. Sect. C Cryst. Struct. Commun. 2008, 64, m292-m295. [CrossRef] [PubMed] 
47. Liu, C.-S.; Yan, L.-F.; Chang, Z.; Wang, J.-J. Tetrakis( $\mu$-anthracene-9-carboxylato)bis[(anthracene-9-carboxylato)(2,2'bipyridyl)lanthanum(III)]. Acta Crystallogr. Sect. E Struct. Rep. Online 2008, 64, m15-m16. [CrossRef] [PubMed]

48. Liu, C.-S.; Hu, M.; Zhang, Q. Synthesis and Crystal Structure of a New Dinuclear Holmium(III) Complex with a Bulky AnthraceneBased Carboxylate Ligand. J. Chem. Crystallogr. 2010, 40, 1002-1005. [CrossRef]

49. Wang, Y.-L.; Han, C.-B.; Zhang, Y.-Q.; Liu, Q.-Y.; Liu, C.-M.; Yin, S.-G. Fine-Tuning Ligand to Modulate the Magnetic Anisotropy in a Carboxylate-Bridged Dy 2 Single-Molecule Magnet System. Inorg. Chem. 2016, 55, 5578-5584. [CrossRef]

50. Kusrini, E.; Adnan, R.; Saleh, M.I.; Yan, L.-K.; Fun, H.-K. Synthesis and structure of dimeric anthracene-9-carboxylato bridged dinuclear erbium(III) complex, $\left[\mathrm{Er}_{2}(9-\mathrm{AC})_{6}(\mathrm{DMF})_{2}\left(\mathrm{H}_{2} \mathrm{O}\right)_{2}\right]$. Spectrochim. Acta Part A Mol. Biomol. Spectrosc. 2009, 72, 884-889. [CrossRef] [PubMed]

51. Alvarez, S.; Alemany, P.; Casanova, D.; Cirera, J.; Llunell, M.; Avnir, D. Shape maps and polyhedral interconversion paths in transition metal chemistry. Coord. Chem. Rev. 2005, 249, 1693-1708. [CrossRef]

52. Cirera, J.; Ruiz, E.; Alvarez, S. Stereochemistry and Spin State in Four-Coordinate Transition Metal Compounds. Inorg. Chem. 2008, 47, 2871-2889. [CrossRef]

53. Benelli, C.; Gatteschi, D. Introduction to Molecular Magnetism; Wiley-VCH Verlag GmbH \& Co. KGaA: Weinheim, Germany, 2015; ISBN 9783527690541.

54. Ballentine, L.E.; Griffiths, D. Quantum Mechanics. Am. J. Phys. 1991, 59, 1153-1154. [CrossRef]

55. Zhu, W.-H.; Xiong, X.; Gao, C.; Li, S.; Zhang, Y.; Wang, J.; Zhang, C.; Powell, A.K.; Gao, S. A family of one-dimensional lanthanide complexes bridged by two distinct carboxylate ligands with the Dy analogue displaying magnetic relaxation behaviour. Dalton Trans. 2017, 46, 14114-14121. [CrossRef] [PubMed]

56. Liu, T.-Q.; Yan, P.-F.; Luan, F.; Li, Y.-X.; Sun, J.-W.; Chen, C.; Yang, F.; Chen, H.; Zou, X.-Y.; Li, G.-M. Near-IR Luminescence and Field-Induced Single Molecule Magnet of Four Salen-type Ytterbium Complexes. Inorg. Chem. 2015, 54, 221-228. [CrossRef] [PubMed]

57. Aubin, S.M.J.; Sun, Z.; Pardi, L.; Krzystek, J.; Folting, K.; Brunel, L.-C.; Rheingold, A.L.; Christou, G.; Hendrickson, D.N. Reduced Anionic Mn 12 Molecules with Half-Integer Ground States as Single-Molecule Magnets. Inorg. Chem. 1999, 38, 5329-5340. [CrossRef]

58. Speed, S.; Feng, M.; Fernandez Garcia, G.; Pointillart, F.; Lefeuvre, B.; Riobé, F.; Golhen, S.; Le Guennic, B.; Totti, F.; Guyot, Y.; et al. Lanthanide complexes involving multichelating TTF-based ligands. Inorg. Chem. Front. 2017, 4, 604-617. [CrossRef]

59. Pointillart, F.; Cador, O.; Le Guennic, B.; Ouahab, L. Uncommon lanthanide ions in purely 4f Single Molecule Magnets. Coord. Chem. Rev. 2017, 346, 150-175. [CrossRef]

60. Sheldrick, G.M. A short history of SHELX. Acta Crystallogr. Sect. A Found. Crystallogr. 2008, 64, 112-122. [CrossRef]

61. Sheldrick, G.M. Crystal structure refinement with SHELXL. Acta Crystallogr. Sect. C Struct. Chem. 2015, 71, 3-8. [CrossRef] 